\title{
Nurses in the community: a manpower study
}

\author{
J. HUGHES, P. STOCKTON, J. A. ROBERTS, AND R. F. L. LOGAN \\ From the Department of Community Health, London School of Hygiene and Tropical Medicine
}

SUMMARY High priority is at present being given to the expansion of health visiting and home nursing services as part of the change of emphasis from institutional to community care. The aim of this study was to provide nurse managers in two regional health authorities with basic information about community nurses which could be used for service planning and development. The results of the study emphasise the particular problems of staffing the community nursing service in inner London, where home nurses and health visitors are younger, more recently appointed, and relatively less experienced than staff in other parts of the regions. High turnover rates and chronic recruitment difficulties in inner London prevent nurse managers from maintaining both the level and the quality of the services they aim to provide. Until these problems are remedied there is little prospect of achieving any significant shift in the balance of care in inner London.

During the economic crises of the 1970s, growth in expenditure on health services in Britain has been much reduced. In this context of limited resources, attempts have been made to reduce geographical inequalities in National Health Service provision and to establish priorities in relation to improving services for particular care groups. The redistribution of resources between regions has already begun with the implementation of the recommendations of the Resource Allocation Working Party (Department of Health and Social Security, 1976b) to allocate finance according to population-based indicators of need. The consultative documents (Department of Health and Social Security, 1976a; 1977) emphasise the importance of adjusting the balance of care to provide greater support for all groups of patients in the community.

These changes necessitate a major restructuring of services for some regions, and in this respect the four Thames regions face a particularly difficult task, because they have traditionally relied heavily on hospital services and they have a reduced share of resources under the new formula. As part of the planning process that is being carried out to implement the various recommendations, the North-east and North-west Thames Regional Health Authorities have commissioned studies to investigate medical and nursing resources in the community. This study of the community nursing services is part of their research programme.

The problems involved in changing the balance of care in these two regions are exacerbated by deficiencies in the present provision of primary and community health services. A survey of the distribution of general practitioners, undertaken for the North-east Thames Regional Health Authority by Logan et al. (1978), showed that there is a concentration of elderly and single-handed $\varnothing$ practitioners in the inner London area Recommendations on the organisational prerequisites for good general practice made by the medical profession itself (Department of Health and Social Security, 1971), and the indicators of professional activity discussed by Sidel et al. (1972), suggest that a high proportion of elderly and single-handed GPs working from inadequate premises will severely limit the development of GP-based primary and community health care. However, there is little that the health authority can do, given the existing administrative arrangements, to influence the organisation and provision of general practice within its boundaries.

The health authority is responsible for providing other primary and community health services and developing these to meet local needs. The community nursing services are at present being given priority at national level, and a growth rate in real terms of six per cent per annum is recommended for the home nursing and health visiting services (Department of Health and Social Security, 1977). This proposed development raises questions about the availability of trained nursing staff to ensure that expansion can take place as required. However, apart from the number of nurses employed in the service, no information is collected either nationally or regionally which would be of use for manpower 
planning purposes. No data are available on the characteristics of the present stock of nurses, their recruitment patterns, or their wastage rates, although a data collection system which will remedy this dearth of information is being developed in the Wessex region (Gourlay, 1978).

The aim of our study was to compile some basic information about nurses in the community to provide a data base which would be of use to the nursing management in planning the future manpower needs of the service. The three main objectives were:

(a) To document and analyse the characteristics of community nursing staff, wastage rates, and patterns of recruitment.

(b) To obtain information from nurse managers on the management, organisation, and problems of deployment of community nursing staff.

(c) To identify and explore problem areas and suggest policy strategies to facilitate the development of the community nursing services.

\section{Methods}

Two major considerations in designing the study were that the information should be gathered as quickly as possible, so that rapid feedback could be provided for nurse managers at all levels in the regions, and that there should be minimal expenditure of time and resources by NHS staff. The method chosen by Abel et al. (1976) for the Scottish studies, namely, to approach each nurse employed in the service directly by confidential postal questionnaire, was rejected because of the time and resources that would have been required to ensure a sufficiently high response rate in a large-scale survey of this kind. The data required for the study included the grade, date of birth, sex, marital status, appointment date, qualifications, hours worked, place of residence, and working base of each nurse, all of which are routinely recorded items of personnel information. It was therefore assumed these would be readily available from staff records and the information was obtained directly from this source.

The completeness of the information collected varied between health districts but apart from omissions from the records no reason was found to question the quality of the data, although there was little opportunity to check accuracy or reliability. Major difficulties were encountered in compiling information on those who had left the service during the year before the survey. Ideally, the same data would have been collected about nurses in post and leavers, but there were problems in identifying leavers and in obtaining information about them. Every effort was made to include all leavers, but information from three districts was known to be incomplete and was therefore excluded from the analysis. In the other districts, grade and length of service were the only items of information obtainable for the majority of leavers.

Interviews with the head of the community nursing division in each health district provided background information about the organisation of the service, deployment of staff, and staffing problems.

The data were collected in November 1977 (North-east Thames Region) and in February 1978 (North-west Thames Region). When the surveys had been completed, information had been gathered on 5033 community nurses and auxiliary staff in the two regions. By comparison with the staffing returns of each health district, this figure was estimated to represent $95 \%$ of staff in post at the time of the survey. Table 1 shows the grades and numbers of staff included in the survey, from which midwives, health visitor students, family planning nurses, and agency staff were excluded. This paper focuses on the two largest groups, health visitors and home nurses, which together comprise more than $60 \%$ of the total staff.

Table 1 North-east and North-west Thames Regional Health Authorities' community nursing staff

\begin{tabular}{lcc}
\hline Grade & No. & $\%$ \\
\hline Senior nursing officer & 35 & $0 \cdot 7$ \\
Nursing officer & 181 & 4 \\
Health visitor & 1322 & 26 \\
Home nurse & 1894 & 37 \\
School/clinic nurse & 760 & 15 \\
TB or chest clinic visitor, geriatric visitor & 116 & 2 \\
Community psychiatric nurse & 17 & $0 \cdot 3$ \\
Auxiliary nurse & 626 & 12 \\
Nursery nurse and creche assistant & 82 & 2 \\
TOTAL STAFF IN SURVEY* & 5033 & 100 \\
\hline
\end{tabular}

* November 1977 (North-east Thames Regional Health Authority)

February 1978 (North-west Thames Regional Health Authority).

One of our main concerns in the analysis was to combine the information from the $\mathbf{3 5}$ health districts to take into account the wide social and demographic variation within the two regions. The whole area was divided into three parts on the basis of what was known about their characteristics. The health districts designated as 'inner London'* for the purposes of the study correspond as closely as possible to the Greater London Council inner London boroughs. These are characterised by multiple social deprivation (Holtermann, 1975), including bad housing conditions (Fawcett, 1976), high population mobility (Office of Population

*Camden and Islington AHA, Kensington and Chelsea and Westminster AHA and City and Hackney, Tower Hamlets, South Hammersmith and North Hammersmith health districts. 
Censuses and Surveys, 1978), and high proportions of elderly persons living alone and single-parent families (Imber, 1977). What remained of the regions was divided into two parts, the outer London health districts, ${ }^{* *}$ and the counties outside Greater London (Bedfordshire, Hertfordshire, and Essex Area Health Authorities). When the data were analysed in terms of these three areas, differences in the size and characteristics of the community nursing stock became evident.

\section{Results}

\section{STAFFING LEVELS}

Funded establishment figures and whole-time equivalent (WTE) numbers of staff in post in each health district at the time of the survey were used to calculate two measures of health visitor and home nurse provision in relation to total population served (Table 2). Both measures show higher health visitor and home nurse staffing levels in inner London compared with outer London and the counties. The

**Barking and Havering, Barnet, Brent and Harrow, Enfield and Haringey, Hillingdon and Redbridge and Waltham Forest AHAs and Ealing, Hounslow and Newham health districts. difference between the funded establishment and in-post staffing levels is greatest in inner London, indicating higher vacancy rates in this area than elsewhere in the two regions at the time of the survey. The average staffing levels for the regions conceal wide variations between health districts in the numbers of health visitors and home nurses per head of population, as shown by the range of staffing levels in Table 2. Provision of home nurses shows the greatest variation, but for both grades some districts have more than twice as many staff as others. Although inner London has higher average staffing levels than outer London or the counties, the range within this area is almost as great as within the two regions as a whole.

CHARACTERISTICS OF THE STOCK OF NURSES The age structure of home nurses and health visitors in inner London is different from that in outer London and the counties. A significantly larger proportion of the staff working in inner London are in the youngest age groups, while $28 \%$ of health visitors and $22 \%$ of home nurses in the counties are over 50 , compared with only $15 \%$ in inner London (Table 3).

Table 2 Health visitor and home nurse staffing levels

\begin{tabular}{|c|c|c|c|c|}
\hline \multirow[b]{2}{*}{ Health districts } & \multicolumn{2}{|c|}{$\begin{array}{l}\text { Health visitors (WTE) } \\
\text { per } 100000 \text { population based on: }\end{array}$} & \multicolumn{2}{|c|}{$\begin{array}{l}\text { Home nurses (WTE) } \\
\text { per } 100000 \text { population based on: }\end{array}$} \\
\hline & $\begin{array}{l}\text { Funded } \\
\text { establishments }\end{array}$ & Staff in post & $\begin{array}{l}\text { Funded } \\
\text { establishments }\end{array}$ & Staff in post \\
\hline $\begin{array}{l}\text { Inner London } \\
\text { Outer London } \\
\text { Counties }\end{array}$ & $\begin{array}{l}22 \\
18 \\
18\end{array}$ & $\begin{array}{l}19 \\
16 \\
17\end{array}$ & $\begin{array}{l}34 \\
25 \\
23\end{array}$ & $\begin{array}{l}29 \\
24 \\
22\end{array}$ \\
\hline North-east Thames and North-west Thames RHAs & 19 & 17 & 26 & 24 \\
\hline $\begin{array}{l}\text { RANGE } \\
\text { All districts } \\
\text { Inner London districts }\end{array}$ & $\begin{array}{l}13-26 \\
15-26\end{array}$ & $\begin{array}{l}12-25 \\
13-25\end{array}$ & $\begin{array}{l}17-39 \\
25-39\end{array}$ & $\begin{array}{l}15-35 \\
22-35\end{array}$ \\
\hline
\end{tabular}

Table 3 Age structure of health visitors and home nurses

\begin{tabular}{|c|c|c|c|c|c|}
\hline \multirow[b]{2}{*}{ Health districts } & \multicolumn{4}{|c|}{ Age groups (years) } & \multirow{2}{*}{$\begin{array}{l}\text { No. } \\
(100 \%)\end{array}$} \\
\hline & $<30$ & $30-39$ & $40-49$ & $50+$ & \\
\hline $\begin{array}{l}\text { HEALTH VISITORS* } \\
\text { Inner London } \\
\text { Outer London } \\
\text { Counties }\end{array}$ & $\begin{array}{l}32 \\
19 \\
13\end{array}$ & $\begin{array}{l}38 \\
27 \\
23\end{array}$ & $\begin{array}{l}15 \\
31 \\
36\end{array}$ & $\begin{array}{l}15 \\
23 \\
28\end{array}$ & $\begin{array}{l}277 \\
504 \\
534\end{array}$ \\
\hline North-east Thames and North-west Thames RHAs & 20 & 28 & 30 & 23 & 1315 \\
\hline $\begin{array}{l}\text { HOME NURSES** } \\
\text { Inner London } \\
\text { Outer London } \\
\text { Counties }\end{array}$ & $\begin{array}{l}24 \\
11 \\
11\end{array}$ & $\begin{array}{l}33 \\
35 \\
30\end{array}$ & $\begin{array}{l}29 \\
36 \\
38\end{array}$ & $\begin{array}{l}15 \\
18 \\
22\end{array}$ & $\begin{array}{l}405 \\
761 \\
714\end{array}$ \\
\hline North-east Thames and North-west Thames RHAs & 14 & 33 & 35 & 19 & 1880 \\
\hline
\end{tabular}


Variations in the stability of the stock of nurses within the regions are indicated by length of service profiles (Table 4). In inner London, 53\% of health visitors and $33 \%$ of home nurses have been in post for less than two years, compared with the more even distributions of length of service in both outer London and the counties.

It was not possible to collect details of previous nursing experience, although this may be reflected in a nurse's age and length of service. For health visitors, however, the number of years since qualification provides an estimate of experience in health visiting, particularly for recently qualified staff. Variations in health visiting experience are shown in Table 5. In inner London, the proportion of health visitors who qualified within the last two years $(38 \%)$ is significantly higher than in outer London $(27 \%)$ or the counties $(21 \%)$, where the majority of health visitors qualified more than five years ago.

Inner London also has more than twice the proportion of unmarried health visitors and home nurses compared with elsewhere in the regions. This is not entirely due to the predominance of younger staff in this area, as inner London has a higher percentage of unmarried staff in all age groups (Table 6).

Table 4 Length of service distributions for health visitors and home nurses

\begin{tabular}{|c|c|c|c|c|c|c|}
\hline \multirow[b]{2}{*}{ Health districts } & \multicolumn{5}{|c|}{ Months of service } & \multirow{2}{*}{$\begin{array}{l}\text { No. } \\
(100 \%)\end{array}$} \\
\hline & $<12$ & $12-23$ & $24-59$ & $60-119$ & $120+$ & \\
\hline $\begin{array}{l}\text { HEALTH VISITORS* } \\
\text { Inner London } \\
\text { Outer London } \\
\text { Counties }\end{array}$ & $\begin{array}{l}30 \\
19 \\
18\end{array}$ & $\begin{array}{l}23 \\
18 \\
17\end{array}$ & $\begin{array}{l}30 \\
31 \\
30\end{array}$ & $\begin{array}{r}8 \\
18 \\
20\end{array}$ & $\begin{array}{r}9 \\
15 \\
16\end{array}$ & $\begin{array}{l}280 \\
501 \\
533\end{array}$ \\
\hline North-east Thames and North-west Thames RHAs & 21 & 18 & 30 & 17 & 14 & 1314 \\
\hline $\begin{array}{l}\text { HOME NURSES** } \\
\text { Inner London } \\
\text { Outer London } \\
\text { Counties }\end{array}$ & $\begin{array}{l}20 \\
16 \\
13\end{array}$ & $\begin{array}{l}13 \\
12 \\
13\end{array}$ & $\begin{array}{l}41 \\
36 \\
34\end{array}$ & $\begin{array}{l}15 \\
20 \\
23\end{array}$ & $\begin{array}{l}11 \\
16 \\
17\end{array}$ & $\begin{array}{l}408 \\
765 \\
716\end{array}$ \\
\hline North-east Thames and North-west Thames RHA's & 16 & 12 & 36 & 20 & 16 & 1889 \\
\hline
\end{tabular}

$x^{2}=41.4 \quad P<0.001$

$* x^{2}=31.2 \quad P<0.001$

Table 5 Number of years since completion of health visitor training

\begin{tabular}{|c|c|c|c|c|c|}
\hline \multirow[b]{2}{*}{ Health districts } & \multicolumn{4}{|c|}{ Years since qualification } & \multirow{2}{*}{$\begin{array}{l}\text { No. } \\
(100 \%)\end{array}$} \\
\hline & $<2 *$ & $2-4$ & $5-9$ & $10+$ & \\
\hline $\begin{array}{l}\text { Inner London } \\
\text { Outer London } \\
\text { Counties }\end{array}$ & $\begin{array}{l}38 \\
27 \\
21\end{array}$ & $\begin{array}{l}26 \\
19 \\
23\end{array}$ & $\begin{array}{l}18 \\
19 \\
19\end{array}$ & $\begin{array}{l}18 \\
34 \\
36\end{array}$ & $\begin{array}{l}249 \\
454 \\
479\end{array}$ \\
\hline North-east Thames and North-west Thames RHAs & 27 & 22 & 19 & 32 & 1182 \\
\hline
\end{tabular}

$x^{2}=56.6 \mathrm{P}<0.001$

Qualified in 1977 or 1976.

Table 6 Marital status by age for health visitors and home nurses

\begin{tabular}{|c|c|c|c|c|}
\hline \multirow[b]{2}{*}{ Health districts } & \multicolumn{3}{|c|}{ Age group (years) } & \multirow{2}{*}{$\begin{array}{l}\text { \% unmarried, } \\
\text { all age groups }\end{array}$} \\
\hline & $<30$ & $30-39$ & $50+$ & \\
\hline \multirow{2}{*}{$\begin{array}{l}\text { HEALTH VISITORS } \\
\text { Inner London } \\
\text { Outer London } \\
\text { Counties }\end{array}$} & \multicolumn{3}{|c|}{ Percentage unmarried } & \multirow[b]{2}{*}{$\begin{array}{l}55 \\
25 \\
21\end{array}$} \\
\hline & $\begin{array}{l}61 \\
22 \\
22\end{array}$ & $\begin{array}{l}58 \\
30 \\
21\end{array}$ & $\begin{array}{l}39 \\
33 \\
29\end{array}$ & \\
\hline North-east Thames and North-west Thames RHAs & 38 & 38 & 32 & 31 \\
\hline $\begin{array}{l}\text { HOME NURSES } \\
\text { Inner London } \\
\text { Outer London } \\
\text { Counties }\end{array}$ & $\begin{array}{l}56 \\
31 \\
22\end{array}$ & $\begin{array}{l}32 \\
10 \\
12\end{array}$ & $\begin{array}{l}35 \\
14 \\
20\end{array}$ & $\begin{array}{l}35 \\
12 \\
13\end{array}$ \\
\hline North-east Thames and North-west Thames RHAs & 39 & 17 & 21 & 18 \\
\hline
\end{tabular}


A significantly lower proportion of part-time health visitors and home nurses are employed in inner London (14\% and $7 \%$ respectively) compared with outer London $(27 \%$ and $20 \%)$ and the counties (24\% and $17 \%)$. Although a higher proportion of married nurses work part-time, the difference between inner London and the rest of the regions is found in both married and unmarried groups.

These characteristics of the stock of nurses seem unlikely to change in the short term, since the recruits to both grades in the last year show the same intra-regional variation as the staff in post.

\section{TURNOVER OF STAFF}

Estimated wastage rates* for the year before the survey indicate the movement of staff out of each health district. A higher overall wastage rate was found for health visitors (20\%) than for home nurses (12\%), but within each grade the rate in inner London is the highest. In inner London, the wastage rate for health visitors is $27 \%$, compared with $21 \%$ in outer London and $14 \%$ in the counties. Crude wastage rate, however, can be a rather misleading statistic (Ashdown, 1970; Mercer and Long, 1977), especially when there are differences in the length of service profiles within the regions. Wastage rates were therefore calculated for each length of service group and Fig. 1 shows the probability of a health visitor with a particular length of service leaving.

Although $40 \%$ of health visitors leaving the inner London health districts had completed less than two years' service, the high wastage rates in this area are

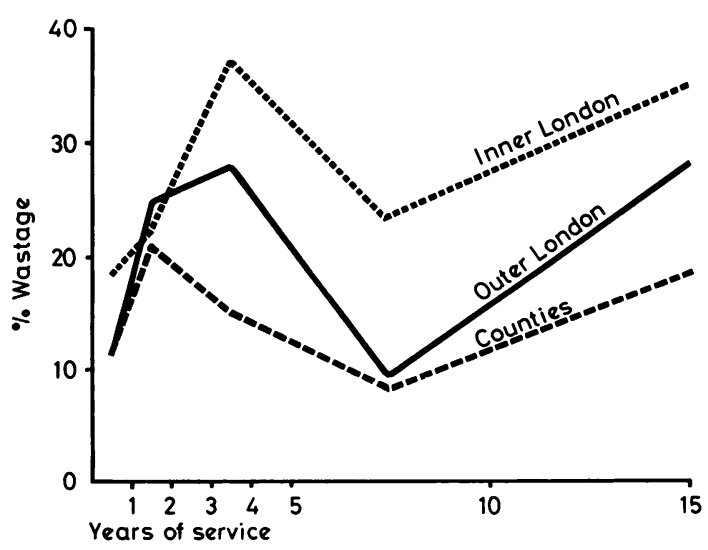

Fig. 1 Health visitor wastage rates controlled for length of service.

\footnotetext{
-Wastage rate: The number of leavers during the last year expressed as a percentage of the total number in that grade in post at the time of the survey. (Wastage rates calculated on WTE rather than on individual figures, where these were available, produced very similar results).
}

not completely accounted for by high turnover among recently recruited staff. For all lengths of service, except in the second year, wastage rates are higher in inner London than in outer London, which in turn has higher wastage rates than the counties.

Fig. 2 shows that the pattern for home nurses differs from that for health visitors. The peak wastage in inner London occurs within the second year of service, which accounts for the majority of home nurse wastage. Even so, inner London has higher wastage rates than both outer London and the counties for all lengths of service.

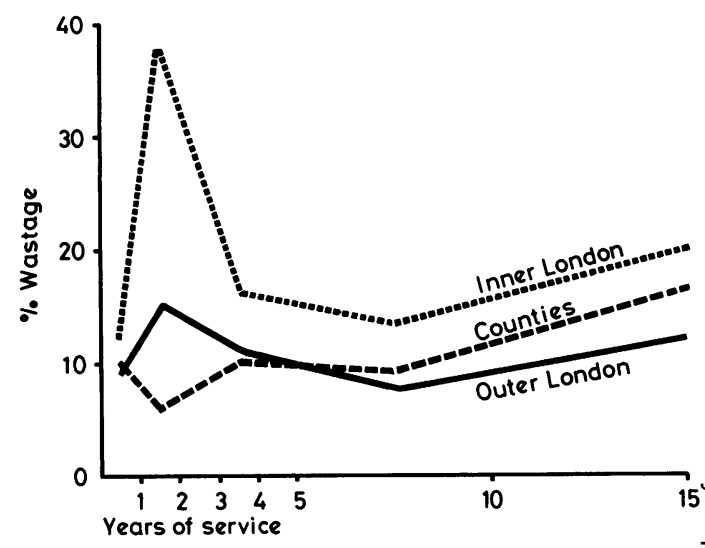

Fig. 2 Home nurse wastage rates controlled for length of service.

ORGANISATION AND STAFFING PROBLEMS

Interviews with nurse managers in each of the 35 health districts were structured to focus on the organisation of community nursing services and staffing problems encountered in the last year. Important differences were found between the inner London and suburban districts both in the organisation of services and in the typical problems described by nurse managers.

In the counties and parts of outer London, the attachment of community nurses to GPs is well established, but in the rest of the London districts there are wide variations in the extent to which attachments or alignments have been developed and in how these are at present functioning. Nurse managers in inner London cited the high proportion of single-handed GPs with widely dispersed patients, and the high mobility of the population of the area, to support their decisions to deploy community nurses geographically, and make attachments selectively to health centres or large group practices.

In the interviews with nurse managers in the London area, there was much discussion of current staffing problems. The recruitment of trained and 
experienced health visitors was described as virtually impossible, with advertisements for staff yielding little response. There were, however, many applicants for health visitor training, and allocated places were easily filled, although difficulties arose in some districts when a high proportion of students either failed to complete the course or, as often happened, did not fulfil their two-year service commitment.

Recruitment of home nurses was easier, and high wastage from this grade does not create quite the same problems for nurse managers, although they reported that district nurse-trained staff rarely apply for posts and that there is a chronic shortage of experienced SRNs in inner London. In the counties, nurse managers stated that trained and experienced staff were available for recruitment, although vacancies were few so they were rarely required. All nurse managers envisaged that staffing the home nursing service would become more difficult when the new longer training requirements were introduced.

Contrasts in the nurse managers' experiences of staffing problems are consistent with the survey findings. The data enabled us to quantify the differences in the characteristics of community nurses within the regions and to estimate the magnitude of the particular problems these imply.

\section{Discussion}

The reports of nurse managers in inner London, substantiated by the survey findings, clearly demonstrate the day-to-day management problems involved in providing a community nursing service. What are the wider implications of these findings for the delivery of community nursing care and, in particular, for the development of this service in inner London? Our interpretations must rely on widely held but as yet untested assumptions about the determinants of quality of care. High wastage rates, short length of service, and nurses' inexperience can be argued to affect adversely the quality of care provided in three ways: by interrupting the continuity of care to the patient, disrupting the development of relationships with colleagues and other professionals, and making it difficult to achieve a balance of experience in the nursing team.

High turnover rates also have important cost implications for the community nursing service. In inner London, the administrative costs of recruitment and termination and training costs, which include the hidden cost of the time needed for new recruits to get to know a district, its patients, practices and procedures, are likely to be high in proportion to the number of staff employed.
The high percentages of young nurses and recently qualified health visitors employed in inner London were of particular concern to nurse managers, because both imply relative inexperience. Nursing officers reported difficulty in achieving the required balance of experience in their nursing and health visiting teams. For health visitors, this problem of the mix of experience is exacerbated by the national shortage of staff, which means that recruitment is mainly of unqualified staff for secondment to health visitor training courses. In districts where turnover is small, staffing levels are maintained by an annual input of newly trained health visitors and a small proportion of experienced staff. In inner London, however, according to nurse managers, recruitment of experienced staff is virtually impossible and more newly trained health visitors are required to maintain staffing levels. Even so, the higher turnover rates in this area inevitably result in vacancies which cannot be filled, as reflected in the gap between establishment and in post staffing levels.

It is not clear how present staffing levels relate to the need for community nurses, as there are no better guidelines for evaluation than the ratios of nurses and health visitors to total population recommended by the Department ot Health and Social Security (DHSS, 1977). More sophisticated formulae are required to take into account the health and social needs of the community served, such as that suggested for home nurse allocation by Down and Snaith (1975), as well as the organisational aspects, especially the mix of staff and their deployment.

The marital status of staff and the number of part-timers are not problems in themselves, although it is unclear whether full-time posts are offered in inner London as a matter of policy or whether they reflect the preferences of available staff. Marital status is related to the age of the nurses and together these factors indicate that the 'life-stage' of the inner London staff is different from that of those employed elsewhere in the regions. This has implications for the potential mobility of these nurses, who are less likely to have dependants than nurses in the rest of the regions. They may also have different career intentions and attitudes to, and expectations about, their work.

The major problems facing the inner London health districts, a high turnover of nurses together with the relative inexperience of recruits to the service, could clearly be alleviated by attempting to retain staff or to recruit more mature and experienced nurses, but further studies are required to identify the best policy strategies for achieving these aims.

Possible solutions to the wastage problem cannot be evaluated without additional information about 
the movement of staff, which entails discovering more about the characteristics of leavers from the service, their reasons for leaving, and the conditions under which they might have stayed. Present conditions of service and certain fringe benefits vary among area health authorities and even among health districts. Improving them is an obvious strategy which might be adopted both to retain present employees and to attract staff to a district. In our interviews nurse managers were quick to suggest changes which they thought might increase recruitment or stabilise staff, and some had in fact been able to introduce their ideas, for example, offering interest-free loans for the purchase of season tickets. Unfortunately the effectiveness of these innovations is rarely monitored and their impact on the service would be difficult to determine without a better understanding of the dynamics of manpower in the community nursing service.

Other important variables which may affect the stability of staff or the relative attractiveness of employment in a health district are nurses' and health visitors' workloads and the characteristics of their patients and clients. It is likely that these factors, and aspects of the physical environment of inner London, combine to make community nursing there a particularly demanding and stressful job. Further research is planned to document nurses' and health visitors' perceptions of their work, its rewards and frustations, in order to identify possible causes of the high turnover rates in inner London and the reasons why this area is unattractive to certain groups of staff. It is possible that the work of the community nursing service in inner London is so different from that in suburban and rural areas that the only effective solutions to present staffing problems may lie in radical organisational changes or a rethinking of staffing requirements.

In the short term, the shortage of staff in general, and of experienced nurses and health visitors in particular, may be eased by measures which facilitate the return of nurses after a break in employment. The existence of a pool of nurses who are not currently working is assumed, but we know little about its size and location. How do community nurses view the possibilities of returning to work, taking into account their family commitments, career prospects, and competing employment opportunities? Recruitment and staffing policies may require modification to encourage these nurses to return, but before any changes are made more information is needed about selection procedures and how explicit or implicit recruitment policies are affecting the shape of the service. Although our study used all the data currently collected administratively within the service, the additional information outlined above is essential for accurate prediction of wastage, forecasting future staffing needs, and developing a planning strategy for the community nursing service.

\section{Conclusion}

Although there are still many gaps in our knowledge, this study has met the objectives of quantifying some of the characteristics of the stock of community nurses in the two regions and identifying present staffing difficulties. In particular it has indicated the complexity of the problem of achieving an adequately staffed community nursing service which provides continuity of care.

If the two regions are to be successful in shifting the emphasis of care to the community, the problems specific to inner London require particular attention. Unless they can be alleviated, it seems unlikely that nursing teams in the community will be able to undertake the central role in primary health care which recent policy statements have envisaged for them.

This study was supported by the North-east and North-west Thames Regional Health Authorities. We thank the nursing officers in the two regions for their co-operation during the survey and Mrs. Lesley Williams for her assistance throughout the study.

Reprints from Jane Hughes, Department of Community Health, London School of Hygiene and Tropical Medicine, Keppel Street, London WC1E 7HT.

\section{References}

Abel, P. M., Farmer, P. J., Hunter, M. H. S., and Shipp, P. J. (1976). Nursing manpower 1 and 2. Nursing Times, January 1/8, 1-4; January $15,5-7$.

Ashdown, P. L. (1970). Wastage and turnover. In Some Statistical Techniques in Manpower Planning. Civil Service College Occasional Papers No. 25, 8-15. HMSO: London.

Department of Health and Social Security (1971). The Organisation of Group Practice: a Report of the Subcommittee of the Standing Medical Advisory Committee. HMSO: London.

Department of Health and Social Security (1976a). Priorities for Health and Personal Social Services in England. HMSO: London.

Department of Health and Social Security (1976b). Sharing Resources for Health in England. Final Report of the Resource Allocation Working Party. HMSO: London.

Department of Health and Social Security (1977). The Way Forward. HMSO: London.

Down, J., and Snaith, A. H. (1975). The deployment of home nurses. British Journal of Preventive and Social Medicine, 29, 53-57.

Fawcett, J. (1976). Areas of Housing Deprivation. Census Indicators of Urban Deprivation, Working Note No. 13. Department of the Environment: London. 
Gourlay, J. R. (1978). Manpower planning in the NHS. Health Services Manpower Review, 4, (3), 20-22.

Holtermann, S. (1975). Areas of urban deprivation in Great Britain: An analysis of 1971 census data. Social Trends. 6 , 33-46. HMSO: London.

Imber, V. (1977). A Classification of the English Personal Social Services Authorities. DHSS Statistical and Research Report Series No. 16. HMSO: London.

Logan, R. F. L., Roberts, J. A., and Stockton, P. (1978). Report on Manpower in General Practice. Department of Community Health, London School of Hygiene and Tropical Medicine (mimeo).

Mercer, G., and Long, A. (1977). The turnover of labour in nursing, parts 1 and 2. Health Services Manpower Review, 3, (3), 8-13; (4), 6-10.
Office of Population Censuses and Surveys (1978). Census 1971 Great Britain Migration Tables (10\% sample), pp. 1-3. HMSO: London.

Scottish Home and Health Department (1976). A profile of qualified nurses working in the Community Nursing Service in 1973. Nursing Manpower Report No. 7. HMSO: Edinburgh.

Sidel, V. W., Jefferys, M., and Mansfield, P. J. (1972). General practice in the London Borough of Camden: report of an enquiry in 1968. Journal of the Royal College of General Practitioners, 22, Supplement No. 3. 